\title{
INTRAOPERATIVE DIFFICULTIES IN LAPAROSCOPIC CHOLECYSTECTOMY
}

\author{
S.K. Sahu ${ }^{凶}$, A. Agrawal, P.K. Sachan \\ Department of General Surgery, Himalayan Institute of Medical Sciences
}

\begin{abstract}
INTRAOPERATIVE DIFFICULTIES IN LAPAROSCOPIC CHOLECYSTECTOMY (Abstract): INTRODUCTION: Laparoscopic surgery has certain technical limitations like loss of three-dimensional perception, a relatively limited and fixed view of operative field, indirect contact with intraabdominal structures, and limited tactile feedback during dissection and manipulation of tissues. This makes operation difficult sometimes and leads to conversion to open cholecystectomy. AIM: The aim of the study was to study the intraoperative difficulties in Laparoscopic Cholecystectomy. MATERIAL AND METHODS: This is a prospective study over a period of 12 months in the Department of General Surgery at Himalayan Institute of Medical Sciences, HIHT University, Dehradun, Uttarakhand, India. Difficult Laparoscopic Cholecystectomy was defined in those procedures which exceeded 90 minutes in duration and or converted to open procedure. Per operative difficulties were classified and studied in the following steps during the procedure: 1) Creation of the pneumoperitoneum; 2) Separation of all adhesions; 3) Skeletonization, ligation and division of cystic artery and cystic duct; 4) Excision of Gall Bladder from the gall bladder fossa of the liver bed; 5) Extraction of Gall Bladder. RESULT: 200 patients who underwent Laparoscopic Cholecystectomy presenting to our hospital from March 2011 to February 2012 were included in this study. Out of 200 laparoscopic cholecystectomy (LC) 130 (65\%) were easy and $70(35 \%)$ were difficult. Out of these 70 difficult cases $12(6 \%)$ required conversion to open cholecystectomy. The conversion rate was higher in the age group of $>60$ years. The maximum difficulty occurred while separating the adhesions $75.71 \%$ out of 70 cases. Maximum difficulty while performing this step of LC was found in patients with Previous Abdominal Surgery 8 (50\%). Maximum number of adhesions and difficulty separating them was seen in patients with acute cholecystitis $22(41.50 \%)$. Out of 70 difficult cases there were $39(55.71 \%)$ cases in which skeletonization, ligation and division of cystic artery and duct was difficult. Maximum difficulty in this step of LC was seen in patients with abnormal callot's anatomy $20(51.28 \%)$. Maximum conversion rate was seen with patients having abnormal callot's anatomy 35\%. CONCLUSIONS: Previous abdominal surgery, intrahepatic gallbladder, multiple large calculi, very thick walled gallbladder, acute cholecystitis and abnormal callot's anatomy are the difficult factors to operate upon and increases the operating time. Acute cholecystitis and abnormal callot's anatomy are the two conditions in which the conversion rate is higher.
\end{abstract}

\section{KEY WORDS: GALL BLADDER; LAPAROSCOPIC SURGERY; DIFFICULT LAPAROSCOPIC CHOLECYSTECTOMY; CALOT'S TRIANGLE}

SHORT TITLE: Difficulties in laparoscopic cholecystectomy

HOW TO CITE: Sahu SK, Agrawal A, Sachan PK. Intraoperative difficulties in laparoscopic cholecystectomy. Jurnalul de chirurgie (Iaşi). 2013; 9(2): 149-155. DOI: 10.7438/1584-9341-9-2-5.

\section{INTRODUCTION}

The first laparoscopic cholecystectomy (LC) using keyhole approach was done by Professor Mouret of Lyon, France in 1987, when he was completing a gynaecologic laparoscopy on a woman also suffering from symptomatic gall stones, he removed it laparoscopically instead of opening up. 
Dr. Eddie Reddick reported 100 cases of laparoscopic cholecystectomy in 1989. The classical four port technique of LC as described by Reddick became the most widely adopted technique. LC was considered by most to be at its zenith since its inception in the early 1990s and is also now done by 2 and 3 ports. When LC was started, only simple gall stone disease was considered as indication. With increasing expertise and introduction of newer instruments, acute cholecystitis has also become one of the indications for LC. Now any type of calculus cholecystitis can be managed by laparoscopic method. The skill of the surgeon, experience in laparoscopic techniques and thorough knowledge of the risk factors are important for laparoscopic management of gall stone disease in difficult situation without increasing the morbidity. [1]

Laparoscopic surgery has certain technical limitations like loss of threedimensional perception, a relatively limited and fixed view of operative field, indirect contact with intraabdominal structures, and limited tactile feedback during dissection and manipulation of tissues. This makes operation difficult sometimes and leads to conversion to open cholecystectomy. The definition of "difficult laparoscopic cholecystectomy (LC)" is inconsistent. The term difficult cholecystectomy refers to multiple technical intra-operative difficulties that increases the risk complications and significantly prolongs operation time. [2, 3]

The aim of the study was to study the intraoperative difficulties in LC.

\section{MATERIAL AND METHODS}

This study was carried out over a period of 12 months prospectively in the Department of General Surgery at Himalayan Institute of Medical Sciences, HIHT University, Dehradun, Uttarakhand, India. All the patients who underwent LC presenting to our hospital were included in this study. A sample size of 200 was included in the study. Exclusion criteria includes preoperatively proven gall bladder malignancy, refractory coagulopathy, severe cardio-pulmonary disease, as these patients cannot tolerate $\mathrm{CO}_{2}$ pneumoperitoneum and patients unfit for general anaesthesia due to any other reason. Total duration of surgery from the insertion of veress needle to the closure of port site and conversion to open cholecystectomy, if any and the cause of conversion were also studied. Surgeons with experience of more than 100 laparoscopic cholecystectomies did all the surgeries in this study.

Difficult LC was defined in those procedures which exceeded 90 minutes in duration and or converted to open procedure.

Per operative difficulties were classified and studied in the following steps during the procedure:

1) Creation of the pneumoperitoneum;

2) Separation of all adhesions;

3) Skeletonization, ligation and division of cystic artery and cystic duct;

4) Excision of gall bladder (GB) from the gall bladder fossa of the liver bed;

5) Extraction of GB.

Overlapping of these intra operative difficulties were recorded and considered while doing the statistical analysis. The data collected was represented in the form of bar diagram and pie diagrams. The results have been analysed by using unpaired $t$-test.

\section{RESULTS}

This study was carried out over a period of 12 months from March 2011 to February 2012, prospectively in the Department of General Surgery at Himalayan Institute of Medical Sciences, HIHT University, Dehradun, Uttarakhand, India. 200 patients who underwent LC presenting to our hospital were included in this study.

Out of 200 LC, 130 (65\%) were easy and $70(35 \%)$ were considered as difficult. Out of these 70 difficult cases 12 $(6 \%)$ required conversion to open cholecystectomy.

All those cases which were converted from laparoscopic to open cholecystectomy were included in the difficult laparoscpic 
entity irrespective of the timing of conversion (Table I, II).

Table I Duration of surgery $(n=200)$

\begin{tabular}{lccc}
\hline \multicolumn{1}{c}{ Time (mins) } & $n(\%)$ & Male & Female \\
\hline$<30$ & 0 & 0 & 0 \\
$31-60$ & $60(30 \%)$ & 14 & 46 \\
$61-90$ & $70(35 \%)$ & 19 & 51 \\
$>91$ & $58(29 \%)$ & 20 & 38 \\
Conversions & $12(6 \%)$ & 4 & 8 \\
\hline
\end{tabular}

Table II Laparoscopic cholecystectomy group $(n=200)$

\begin{tabular}{lcc}
\hline \multicolumn{1}{c}{ Time } & $n$ & Percentage \\
\hline Difficult as per timing & 58 & $29 \%$ \\
Conversion & 12 & $6 \%$ \\
Easy & 130 & $65 \%$ \\
\hline
\end{tabular}

The conversion was also seen highest in the age group of $>60$ years. In females 3 $(1.5 \%)$ and among males the conversion was seen highest in age group of 51-60 years 2 (1\%) (Fig. 1).

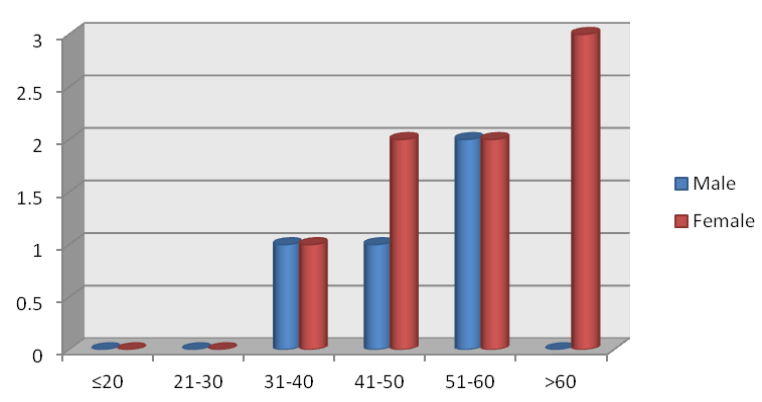

Fig. 1 Age and sex distribution in converted patients

Table III Distribution of difficulty according to creation of pneumoperitoneum $(n=16)$

\begin{tabular}{lcc}
\hline Creation of pneumoperitoneum & $n$ & Percentage \\
\hline Previous abdominal surgery & 8 & $50 \%$ \\
Diffuse peritonitis & 1 & $6.25 \%$ \\
Cholecystitis & 0 & 0 \\
Pancreatitis & 0 & 0 \\
Obesity & 7 & $43.75 \%$ \\
\hline
\end{tabular}

Out of 70 difficult cases pneumoperitoneum creation was found to be difficult in $16(22.85 \%)$ cases. Maximum difficulty while performing this step of LC was found in patients with Previous Abdominal Surgery 8 (50\%) (Table III).

There were $53(75.71 \%)$ patients who had difficulty in separating adhesions (Fig. 2). Maximum number of adhesions and difficulty separating them was seen in patients with acute cholecystitis 22 (41.50\%) (Table IV).

Fig. 2 Difficult spectrum

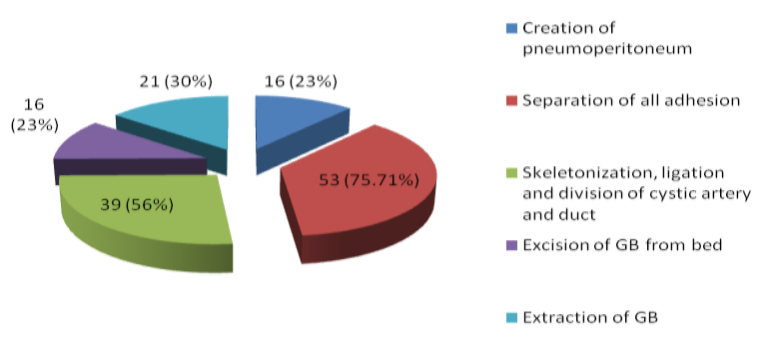

Table IV Distribution of difficulty according to separation of all adhesion $(n=53)$

\begin{tabular}{lcc}
\hline \multicolumn{1}{c}{ Separation of all adhesion } & $n$ & Percentage \\
\hline Acute cholecystitis & 22 & $41.50 \%$ \\
Acute pancreatitis & 4 & $7.54 \%$ \\
Post ERCP cholangitis & 12 & $22.64 \%$ \\
Cirrhotic liver & 6 & $11.32 \%$ \\
Previous abdominal surgery & 9 & $16.98 \%$ \\
\hline
\end{tabular}

Out of 70 difficult cases there were 39 $(55.71 \%)$ cases in which skeletonization, ligation and division of cystic artery and duct was difficult. Maximum difficulty in this step of LC was seen in patients with abnormal callot's anatomy $20(51.28 \%)$ (Table V).

Table V Distribution of difficulty according to skeletonization, ligation and division of cystic artery and duct $(n=39)$

\begin{tabular}{lcc}
\hline \multicolumn{1}{c}{$\begin{array}{c}\text { Skeletonization, ligation \& } \\
\text { division of cystic artery \& duct }\end{array}$} & $n$ & Percentage \\
\hline Short \& wide cystic duct & 16 & $41.02 \%$ \\
$\begin{array}{l}\text { Anomalous vessel } \\
\begin{array}{l}\text { Abnormal Callot's triangle } \\
\text { anatomy }\end{array}\end{array}$ & 3 & $7.69 \%$ \\
\hline
\end{tabular}

There were $16(22.85 \%)$ patients in which, GB dissection from liver was 
difficult (Table VI). Maximum difficulty was encountered in this step of LC was due to Intrahepatic GB 9 (56.25\%).

Table VI Difficulty according to excision of GB from bed $(n=16)$

\begin{tabular}{lcc}
\hline \multicolumn{1}{c}{ Excision of GB from bed } & $n$ & Percentage \\
\hline Small and contracted GB & 7 & $43.75 \%$ \\
Intrahepatic GB & 9 & $56.25 \%$ \\
Empyema GB & 0 & 0 \\
\hline
\end{tabular}

Out of 70 difficult cases there were 21 $(30 \%)$ patients in which extraction of GB from anterior abdominal wall was difficult. Maximum difficulty in this particular step of LC was seen in stone packed gallbladders 8 (38.09\%) (Table VII).

Table VII Distribution of difficulty according to extraction of GB $(n=21)$

\begin{tabular}{lcc}
\hline \multicolumn{1}{c}{ Extraction of GB } & $n$ & Percentage \\
\hline Large \& distended GB & 6 & $28.57 \%$ \\
Very thick walled rigid GB & 7 & $33.33 \%$ \\
Multiple calculi & 8 & $38.09 \%$ \\
\hline
\end{tabular}

Out of 70 difficult LC maximum conversion to open cholecystectomy rate was seen in patients with acute cholecystitis and abnormal Callot's anatomy $58.33 \%$ each (Table VIII).

Table VIII Different causes of difficult LC which had conversion $(n=12)$

\begin{tabular}{llc}
\hline & \multicolumn{2}{c}{ Conversions } \\
& $n$ & Percentage \\
\hline Acute cholecystitis & 7 & $58.33 \%$ \\
$\begin{array}{l}\text { Acute pancreatitis } \\
\begin{array}{l}\text { Post ERCP } \\
\text { cholangitis }\end{array}\end{array}$ & 1 & $8.33 \%$ \\
$\begin{array}{l}\text { Abnormal Callot's } \\
\begin{array}{l}\text { Short and wide } \\
\text { cystic duct }\end{array}\end{array}$ & 7 & $25 \%$ \\
$\begin{array}{l}\text { Cirrhotic liver } \\
\text { Small and } \\
\text { contracted GB }\end{array}$ & 1 & $58.33 \%$ \\
\hline
\end{tabular}

Studying the conversions from point of view of individual causes, in difficult LC group, we noted maximum conversion rate in patients having abnormal callot's anatomy 7 from 20 patients (35\%) (Table IX).

Table IX Conversion rate with individual causes

\begin{tabular}{lccc}
\hline $\begin{array}{l}\text { Different causes } \\
\text { of difficult LC }\end{array}$ & $N$ & $n$ & Percentage \\
\hline $\begin{array}{l}\text { Acute cholecystitis } \\
\text { Acute pancreatitis }\end{array}$ & 22 & 7 & $31.8 \%$ \\
$\begin{array}{l}\text { Post ERCP cholangitis } \\
\text { Abnormal Callot's }\end{array}$ & 12 & 3 & $25 \%$ \\
$\begin{array}{l}\text { anatomy } \\
\text { Short and wide cystic } \\
\text { duct }\end{array}$ & 20 & 7 & $35 \%$ \\
$\begin{array}{l}\text { Cirrhotic liver } \\
\text { Small and contracted GB }\end{array}$ & 7 & 2 & $28.57 \%$ \\
\hline
\end{tabular}

$N$ number of patients from difficult LC group

Mean operating time of 58 difficult cases which were not converted to open procedure was $111.48 \pm 16.96$ minutes. Significant factors which increased the operating time were; previous abdominal surgery, intrahepatic gallbladder, multiple large calculi, very thick walled gallbladder, anomalous vessels, large and distended gallbladder (Table X).

Table X Factors association with operating time $(n=58)$

\begin{tabular}{lcc}
\hline \multicolumn{1}{c}{ Factors } & $\begin{array}{c}\text { Operating time } \\
\text { (mean } \pm \text { SD) }\end{array}$ & $\begin{array}{c}P \\
\text { value }\end{array}$ \\
\hline Previous abdominal surgery & $100.45 \pm 17.67$ & $<\mathbf{0 . 0 5}$ \\
Acute cholecystitis & $112.33 \pm 14.37$ & $>0.05$ \\
Pancreatitis & $108.33 \pm 10.40$ & $>0.05$ \\
Obesity & $110 \pm 13.78$ & $>0.05$ \\
Post ERCP cholangitis & $108.33 \pm 29.33$ & $>0.05$ \\
Cirrhotic liver & $111.2 \pm 17.16$ & $>0.05$ \\
Short and wide cystic duct & $107.33 \pm 10.4$ & $>0.05$ \\
Anomalous vessels & $87.85 \pm 27.66$ & $<\mathbf{0 . 0 5}$ \\
Abnormal callot's & $103 \pm 17.6$ & $>0.05$ \\
Intrahepatic GB & $120.55 \pm 24.42$ & $<\mathbf{0 . 0 5}$ \\
Small and contracted GB & $109 \pm 11.4$ & $>0.05$ \\
\hline Large and distended GB & $97.28 \pm 6.1$ & $<\mathbf{0 . 0 5}$ \\
Very thick wall GB & $120 \pm 28.50$ & $<\mathbf{0 . 0 5}$ \\
Multiple Large calculi & $104.5 \pm 21.6$ & $<\mathbf{0 . 0 5}$ \\
\hline Empyema GB & $86.25 \pm 28.39$ & $>0.05$ \\
\hline
\end{tabular}




\section{DISCUSSION}

Creation of pneumoperitoneum is the first step of laparoscopic cholecystectomy and various difficulties can be seen at this step. In our study after analyzing the available literature we have found out the conditions which can make this step of LC difficult. Out of 200 patients, there were 16 patients who were anticipated to have difficulty in creating a pneumoperitoneum. In this maximum anticipation was for the patients who had previous abdominal surgeries $8(50 \%)$ and who were obese 7 (43.5\%). According to Underwood et al, intra abdominal adhesions secondary to previous upper abdominal surgery can tether underlying viscera consequently increases the risk of hollow organ injury during creation of pneumoperitoneum by veress needle and during placement of laparoscopic trocars [4]. A prospective study by $\mathrm{M}$. Hussein et al [5] in obese patients undergoing laparoscopic cholecystectomy stated that only technical problem that necessitated conversion to operation was failure to establish a pneumoperitoneum. Once a pneumoperitoneum was established, each operation followed lines similar to LC in normal-size patients.

Patients with acute cholecystitis have oedema, hypervascularity, venous engorgement and gallbladder distension. Within 72 hours of symptoms the tissue planes are oedematous and inflamed but are easier to dissect, having no adhesions at all. But after 72 hours, the tissue becomes more friable and becomes dangerous and risky to dissect. Increased gall bladder wall thickness is related to the inflammation and fibrosis that follows attacks of cholecystitis and thus may reflect difficulty in delineation of the anatomy during surgery. Problems with acute biliary pancreatitis are extensive adhesions, visual road block due to inflammatory phlegmon in the region of head of pancreas, highly oedematous cystic pedicle and hepatoduodenal ligament, and presence of ascitic fluid. Prior acute pancreatitis results in scarred and fibrosed gall bladder and in dense fibrotic adhesions that renders laparoscopic dissection difficult. $[6,7]$

In our study out of 200 patients who underwent laparoscopic cholecystectomy 22 (11\%) patients presented with acute cholecystitis after $72 \mathrm{hrs}$ of onset of symptoms. Out of 70 difficult cases, there were $54(77.14 \%)$ patients who had difficulty in separating adhesions. Maximum number of adhesions and difficulty separating them was seen in patients with acute cholecystitis $22(40.74 \%)$. Out of 70 difficult cases, there were $4(7.4 \%)$ patients who had difficulty in separating adhesions due to pancreatitis.

Out of 70 difficult cases there were 39 $(55.71 \%)$ cases in which skeletonization, ligation and division of cystic artery and duct was difficult. Maximum difficulty in this step of LC was seen in patients with abnormal callot's anatomy 20 (51.28 \%). In a study conducted by Ajay Anand et al [8] they found $17.61 \%$ patients in their study group who had wide cystic duct. K. Toress et al [9] in their study found that $37.6 \%$ patients had an atypical course of cystic artery. A randomised trial of laparoscopic versus open cholecystectomy for acute and gangrenous cholecystitis by Kiviluoto reported $16 \%$ patients in the LC group requiring conversion and in most cases because severe inflammation distorting the anatomy of Callot's triangle [10].

Pawan Lal et al [11] in their study of 73 patients found that 11 patients $(15.07 \%)$ with contracted gallbladders, 8 laparoscopic cholecystectomies were surgically difficult, and 5 were converted to the open procedure. Patients with a small contracted gall bladder or a trabeculated gall bladder due to heavy stone load and multiple criss cross strictures in the gall bladder lumen, are also candidates at risk where the surgeon would have difficulty in holding the gall bladder [12]. In our study there were $7(3.5 \%)$ cases that had small and contracted GB and $9(4.5 \%)$ cases that had intrahepatic GB, all of these cases were difficult to operate upon. There were 4 (2\%) cases who had empyema GB but were easy to detach from the liver bed. A gall 
bladder may be congenitally partially or completely embedded in the liver parenchyma or may become buried due to recurrent episodes of inflammation. The problem relating to this abnormality is an inability to grasp the fundus of the gall bladder and an absence of avascular plane of dissection between the gall bladder and liver parenchyma, which makes it technically a challenging task [12]. Malik A et al [13] on LC in empyema Gall bladder found that the difficulty level in performing surgery is not as high as stated in literature if the surgery is done by experienced surgeons; they successfully completed LC in $80.59 \%$ of patients with empyema GB.

Thick gall bladder along with large stones can be difficult to remove, thereby preventing its excision hence fascial incision is extended to facilitate its removal [3]. Out of 70 difficult cases there were 21 (30\%) patients in which extraction of GB from anterior abdominal wall was difficult. Maximum difficulty in this particular step of LC was seen in stone packed gallbladders 8 $(38.09 \%)$.

Out of 70 difficult LC maximum conversion to open cholecystectomy was seen in patients with acute cholecystitis and abnormal callot's anatomy $31.8 \%$ each. Maximum conversion was seen in patients who presented after $72 \mathrm{hrs}$ of attack of cholecystitis. There were 7 cases of acute cholecystitis in which conversion took place. Out of these 7 cases 4 cases also had abnormal anatomy at callot's, in one patient there was small and contracted GB in addition to abnormal callot's, 1 patient had history of post ERCP cholangitis and 1 had billiary pancreatitis associated with cholecystitis. The reason for conversion was dense adhesions around the gallbladder and in callot's triangle which made dissection extremely difficult and completely hampering the proceedings.

Significant factors which increased the operating time were: previous abdominal surgery, intrahepatic gallbladder, multiple large calculi, and very thick walled gallbladder. In all of these cases the $P$ value was $<0.05$. Two other factors which came out to be significant were anomalous vessels and large and distended gallbladder. But these two factors did not increased the operating time individually. Small sample size made anomalous vessels significant and patients having large and distended gallbladder were not time consuming to extract them from the abdominal wall. But two factors acute cholecystitis and abnormal callot's anatomy are above all of them and did not come out to be significant. The reason can be explained as maximum numbers of cases were converted to open cholecystectomy because of acute cholecystitis and abnormal callot's anatomy and the mean operating time was also high in both the groups which were almost equal to the mean operating time of the difficult cases.

\section{CONCLUSION}

We conclude that previous abdominal surgery, intrahepatic gallbladder, multiple large calculi, very thick walled gallbladder, acute cholecystitis and abnormal Callot's anatomy are the difficult factors to operate upon and increases the operating time. Acute cholecystitis and abnormal callot's anatomy are the two conditions in which the conversion rate is higher.

\section{CONFLICT OF INTERESTS}

Authors have no conflict of interests to declare.

\section{REFERENCES}

1. Hunter JG, Trus T. Laparoscopic cholecystectomy. In: Nyhus LM, Baker RJ, Fisher JE editors. Mastery of surgery. 3rd ed. Boston: Little brown and company; 1997. p. 1098.

2. Capizzi FD, Brulati FM, Boschi S, et al. Conversion rate in laparoscopic cholecystectomy evaluation from 1993 and current state. Journal of Laparoscopic and Advanced Surgical Technique. 2003; 13(2): 7-13.

3. Palanivelu C. Difficult Laparoscopic Cholecystectomy. In: Parthasarathi R, editor. Art of Laparoscopic Surgery. Textbook and Atlas. 1st ed. India: Jaya Publications; 2005. p. 607-634. 
4. Underwood RA, Soper NJ. Laparoscopic cholecystectomy and choledocholithotomy. In: Blumgart LH, Fong Y editors. Surgery of liver and biliary tract. 3rd ed. London: W.B. Saunders Company Ltd; 2002. p. 709-712.

5. Hussien M, Appadurai IR, Delicata RJ. Laparoscopic cholecystectomy in the grossly obese: 4 years experience and review of literature. HPB Oxford. 2002; 4(4): 157-161.

6. Rattner DW, Ferguson C, Warshal AL. Factors associated with successful laparoscopic cholecystectomy for acute cholecystitis. Ann Surg. 1993; 217(3): 233-236.

7. Nachani J, Supe A. Pre operative prediction of difficult laparoscopic cholecystectomy using clinical and ultrasonographic parameters. Indian J Gastroenterol. 2005; 24: 16-18.

8. Anand A, Pathania BS, Singh G. Conversion in laparoscopic cholecystectomy: an evaluation study J Med Educ. 2007; 9: 171-174.
9. Torres KA, Golonka CA. The course of the cystic artery during laparoscopic cholecystectomy. Folia Morphol. 2005; 68(3): 140-143.

10. Kiviluoto T, Sinen J, Lwkkanen P. Randomized trial of laparoscopic versus open cholecystectomy for acute and gangrenous cholecystitis. The Lancet. 1998; 351: 321-325.

11. Lal P, Agarwal PN, Malik VK. A difficult laparoscopic cholecystectomy that requires conversion to open procedure can be predicted by preoperative USG. JSLS. 2002; 6(1): 59-63.

12. Khanna S. How to predict difficult laparoscopic cholecystectomy and when to convert. [available online at http://www.iages.org.in/media/files/chapter10. pdf. Aug 10 2011]

13. Malik A, Laghari AA, Altaf $\mathrm{K}$, et al. Laparoscopic cholecystectomy in empyema of gall bladder: An experience at Liaquat University Hospital, Jamshoro, Pakistan. $J$ Minim Access Surg. 2007; 3(2): 52-56. 
